\title{
DOI: 10.7596/taksad.v6i4.1139
}

Citation: Salimian, M., Seresht, B., \& Chavoshbashi, F. (2017). The Role of Social Capital in Upgrading the Efficiency of Human Force. Journal of History Culture and Art Research, 6(4), 11961210. doi:http://dx.doi.org/10.7596/taksad.v6i4.1139

\section{The Role of Social Capital in Upgrading the Efficiency of Human Force}

\author{
Masoum Ali Salimian ${ }^{1}$, \\ Behzad Farrokh Seresht ${ }^{2}$, Farzaneh Chavoshbashi ${ }^{3}$
}

\begin{abstract}
For creation of social capital most of advanced universities are intending to find better changing capacity and increase the knowledge level of their personnel and innovate better teaching methods, innovation and entrepreneurship as well. Regarding importance of the issue, the present study intends to evaluate the roles of social capital in upgrading of efficiency of human force besides to evaluate any significant relationship between social capital and efficiency and also any effects of social capital (Bonding, Bridging and Linking) in efficiency of human force and finally present necessary guidelines and proposals as well. Regarding the major question of the research, there is a significant relationship between social capital and upgrading of human force efficiency. The statistical population of this research include all staff of Islamic Azad University-Chaloos branch. Data collection tools include two questionnaires related to social capital and efficiency of human force. After determining the reliability and validity of questionnaire, all of them were divided among sample members. As a conclusion, it was specified that any increase of human force is possible just through social capital (with bonding, bridging and linking dimensions).
\end{abstract}

Keywords: Bonding social capital, Bridging social capital, Linking social capital, Efficiency of human force.

\footnotetext{
${ }^{1}$ Corresponding Author, Department of Public Administration, Chaloos Branch, Islamic Azad University IranChaloos. E-mail: dr.msalimian@yahoo.com

${ }^{2}$ Department of Public Administration, Chaloos Branch, Islamic Azad University Iran-Chaloos.

${ }^{3}$ Department of Cultural Management, West Tehran Branch, Islamic Azad University, Tehran-Iran.
} 


\section{Introduction}

Various economic hypotheses made a great revolution in organizational functions within last decade. Such a revolution has been presented with traditional capital formats such as buildings and equipment for making new capitals. Such intangible capitals play a great role in development and promotion of the organization. The term of capital includes more daily variants. Some of the variants include human capital, customer capital, intelligence capital and health capital. Lots of researches were made on human capital since 1950s by economic researches. Although the primary definitions of human capital theory was applied to measure worker's knowledge in accordance with official academic levels, but the integration of academic levels and economic growth illustrated that more academic records plus work experiences may lead to better efficiency (Brooks \& Nafukho, 2006: 117).

Recently a new form of social capital has been extracted from sociology as a potential and effective force on organizational functions. Social capital would be used as a current resource in social networks and also as an investment for inter-personal relations in markets. Colman (1990) believes that all relationships are estimated with further values in social capital and social relations. In contrast with human capital and traditional assets of organization, social capital is exclusively related to significant social relations for whom people are investing through the time (Sabatini, 2005: 4).

Increase of human force efficiency is one of the major effects of social capital in organizations. Social capital in commercial organizations means an important resource of efficiency. All workers and specialists are obliged to follow up others' recommendations and supports in compliance with a hierarchy system in order to do the jobs. Although hierarchy is a powerful tool but it may be resulted in following cases:

Firstly: In spite of the powerful situation of managers and hierarchy system of the organization, fellows may be effective on final output through some delays in performance of orders and fight with decisions through their aggressive conducts.

Secondly: As we have the completion of jobs through the time, it is necessary to have team and group working. Absolute confidence in commanding structure and/or controlling of standard operational methods could not guarantee any further success (Greve and Benassi, 2003).

Today there is another capital besides human, financial and economic capitals which is named as Social Capital. It is about any contacts and relationships among members of a network and also a valuable resource for creation of orders and mutual confidence and finding the real goals of it. Social Capital has a sociological aspect and is considered as a suitable field for 
humanistic and physical efficiency and a way for finding final success. Those managers and persons in charge who are successful in establishment of social capital could find success as easily as possible. On the other hand, social capitals make more meanings to life as well.

Social capital plays more important roles than physical \& humanistic capitals in organizations and societies. It is like a network for public and group relations among humans, organizations and so on. In lack of social capital, there are no more effects for other forms of capitals. It means finding promotion and cultural/economic completion is so much difficult.

Capital means a live and creative nature. It will enable us to make values and perform any jobs and finding our goals and complete our assignments. When we speak about social capitals, it means that no one is successful without it accordingly.

Social capital plays great roles in social section. It is related to various parameters like confidence, participation, integration, honesty and obligation among all members of a network. It is a valuable resource for creation of orders and mutual confidence. Social capital is a great tool for success. It is a suitable field for efficiency of human \& physical capitals.

Efficiency means an increase in output through increasing an input in a unit. Generally we should consider efficiency as the rate of results and products to total value of used resources. Therefore, we may compare the value of data with the value of the output. The correctness of this evaluation depends upon the organizational characteristics and access rate to data. As a result there are two problems as important as possible. The first problem is completely clear. It means selection of different inputs and outputs. The second one is variety of input/output factors which are mostly qualitative and difficult to measure. For instance, when we are evaluating some learners in a company, it is so much difficult to specify how much the effect of training is on the quality of products. It means that we could not specify which factor has been changed due to the training and/or which factor has changed the quality of products? Some of the probable factors are: Manager's evaluation, Job satisfaction, Exit of service, Absence motivation, Upgrade and Salary. Perhaps all of the mentioned items are effective. (Aspin, 2004: 3). Today most of traditional forms of capital such as buildings, equipment and resources have been changed with regard to wide changes in constructional operations and new capitals have been appeared accordingly. Such intangible capitals play great roles in promotion and development of the organization. Social capital is one of the mentioned important capitals. In contrast with human or physical capital, social capital has a greater meaning than any assets of a person. Increase of human force efficiency is one of the major effects of social capital. It is a great concern of today organizations because it may cause satisfying results and better competitive advantage. Social capital is effective on organizations via different methods including lower exchange costs, lower displace charges of people, 
dividing of knowledge and innovation, risk acceptance and better quality of products. By the way, there are lots of difficulties to make any research about social capital.

Because of lots of dimensions, there is not a direct way for measuring of social capital. Social capital has multi-aspects in a way that researchers think about those factors with the best relationship with their research. On the other hand, it is difficult to measure efficiency. Efficiency is about inputs and outputs while it is so much difficult to specify exact amount of inputs and their effects on outputs. The present study intends to find out following ideals:

- Recognition the real meaning of social capital

- Recognition of the roles of social capital at Islamic Azad University-Chaloos Branch

- Recognition of any relationship between social capital and efficiency of human force at Islamic Azad University- Chaloos Branch.

\section{Theoretical framework \& analytical model}

Putnam has stated various definitions for social capital in his works: "I mean by social capital various specifications of social life. Networks, criteria and confidence may enable the participants to have more involvements for finding their common goals” (Putnam, 1996: 56). The mentioned three factors did not change since than, but there is a new one titled as “Participants” which has benefited from social capital as well. (Baron et al., 2000: 9).

Putnam has separated two types of social capitals including bonding social capital and bridging social capital. The first may connect just members of a special group and omit the others. The second may connect various parts of the society. Of course, any forms of which are applied for specific necessities. Bonding social capital is useful for enrichment of specific interactions and may cause more motivation. It is like adhesive for maintenance of loyalty in groups. Bridging social capital is used for connection to foreign assets and may cause wider identities and interactions (Putnam, 2000: 22-3).

Woodcock has named various forms of social capital as follows:

1) Bonding social capital which may specify any relationships among similar people at similar positions.

2) Bridging social capital includes various connections among farther people such as: colleagues \& friends.

3) Linking social capital may connect non-similar people at non-similar positions. 
Increase of human force output is one of the major effects of social capital. Social capital is an important source in commercial organizations. Greve and Benassi (2003) believe that social capital will lead to four major consequences in economic system:

1- Finding information

2- Knowledge \& innovation transfer \& distribution of technology and methods

3- Applying of complementary knowledge and intending to solve problems

4- Intermediate

The above-mentioned consequences are changing through the time and according to the relevant needs and characteristics. Social capital is so much critical for the start and support of any economic function. As a result, the positive consequences of which are obvious in various fields such as: industry formation, innovative processes, inter-organizational cooperation and entrepreneurship. Social capital will enable the entrepreneurs to collect and combine their resources from various fields and with a new method. In addition, social capital will provide more assists and consults for entrepreneurs and enable them to make better recognition of their duties and reduce any non-fixed conditions. Social capital means inter-organizational cooperation especially in various fields in which we need mutual confidence and replacement and complement of contracts.

According to the various researches in industrial fields, it is obvious that any lack of social capital is really important for finding more growth and innovation. Social capital is also important in any innovative processes because it may cause new chances for removing any non-satisfied needs and combination of resources in new methods. According to the previous studies, social capital will enrich the spiritual output of social capital in knowledge-based systems. Social capital will provide technical consultants by providing innovations and knowledge transfer (Greve and Benassi, 2003).

The most important mechanisms as follows with positive effects on economic functions are possible just through social capital:

1- Lower costs of transactions: Social capital may cause more obligations and reduce the mentioned costs through increase of confidence.

2- Lower costs of people replacement: In case the staff feels that employers have good behavior with them, they will in return conduct as logically as possible. 
3- Dividing of knowledge \& innovation: According to experimental researches, non-official transactions among the personnel may cause better distribution of information and finding great reserves of knowledge and enrichment of producing processes. The mentioned reserves are available just up to the common relationships among all personnel.

4- Risk acceptance: Risk acceptance and entrepreneur behaviors are encouraged by powerful relations in an organization and /or among different organizations. It seems that social capital is related to a wide range of interactions in which personnel feel that they are important and valuable for employers and their colleagues.

5- Promotion of obtained quality: The result of knowledge division is team cooperation and organizational obligations and probably higher quality of products including social capital. In addition, when personnel feel organizational support, there will be an increase in their operation and also reduction of organizational stress (Aspin, 2004: 6).

Fabio Sabatini (2005) studied any relationship between social capital and human force efficiency at small \& medium enterprises of Italy. By the use of structural equations model, he studied the effects of various aspects of social capital. Binding social capital illustrates powerful relations among family members. Bridging social capital illustrates non-official relations among friends and relatives. It has negative effects on human force output and economic functions and humanistic development.

In contrast, linking social capital has positive effects on human force efficiency. Various dimensions of binding social capital are family and local distance among family members, relationship with relatives, quality of any relations among family members and other relatives. Various dimensions of bridging social capital are participation in production \& consumption, any relations among people at sport groups, restaurants, clubs and neighbors. Linking social capital includes work performance without any salary and voluntarily activities. 


\section{Figure 1. Components of Social Capital}
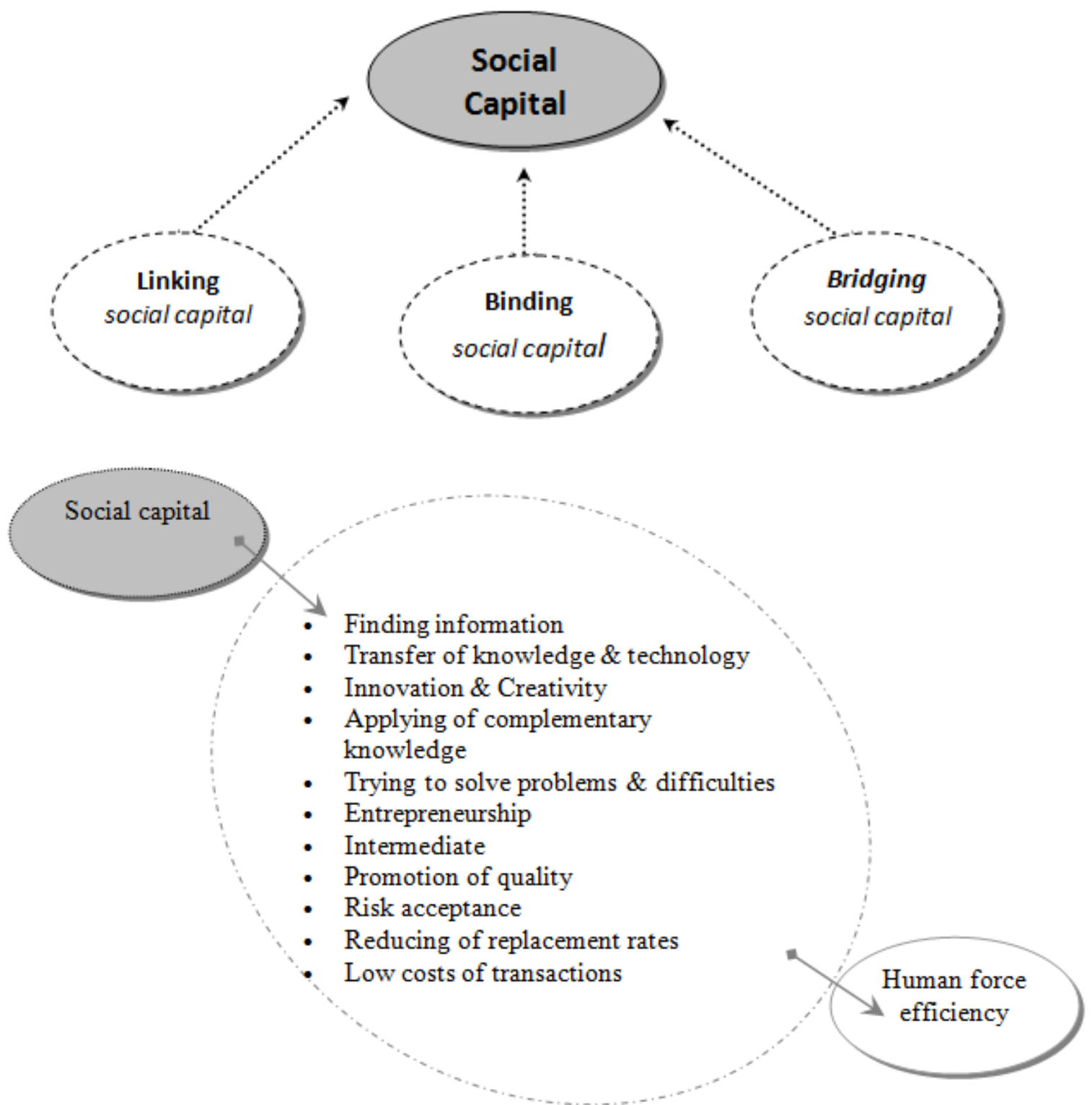

\section{Research hypotheses}

Main hypothesis:

- There is a significant relationship between social capital and upgrading of human force efficiency at Islamic Azad University-Chaloos Branch.

Indirect hypotheses:

1- There is a significant relationship between binding social capital and upgrading of human force efficiency at Islamic Azad University-Chaloos Branch. 
2- There is a significant relationship between bridging social capital and upgrading of human force efficiency at Islamic Azad University-Chaloos Branch.

3- There is a significant relationship between linking social capital and upgrading of human force efficiency at Islamic Azad University-Chaloos Branch.

\section{Statistical population}

Regarding the main question of the present study, statistical population and sample include all professors and occupied personnel at Islamic Azad University-Chaloos branch. We used Cochran Formula for specifying the number of samples. Then we used classified sampling method for specifying the number of members on random basis.

\section{Testing of research hypotheses}

In order to apply a suitable statistical method, firstly we studied relevant assumptions about type of test. Since we had distance research variable, therefore we studied data distribution method through K-S test for this purpose. Upon ensuring about data distribution, we used Pearson correlation tests. Also we considered a significant level for statistical comparisons at mutual level $\mathrm{p}<0.05$.

*Major hypothesis

H1: Research hypothesis:

- There is a significant relationship between social capital and upgrading of human force efficiency at Islamic Azad University-Chaloos Branch.

H0: Null hypothesis:

- There is not a significant relationship between social capital and upgrading of human force efficiency at Islamic Azad University-Chaloos Branch.

If we assume that:

Y: Efficiency

X: Social Capital

$\rho$ : Real correlation coefficient between both variants of efficiency \& social capital at Islamic Azad University-Chaloos Branch.

Regarding the relevant distance among considered studies, therefore we should apply Pearson Correlation test for evaluation of following hypotheses:

$$
\left\{\begin{array}{l}
\boldsymbol{H}_{\mathrm{o}}: \rho=\mathrm{O} \\
\boldsymbol{H}_{1}: \rho \neq \mathrm{O}
\end{array}\right.
$$


Null hypothesis means lack of any relationship between both variants X \& Y. Assumption I means a significant relationship between both variants. Following is the relevant rule for testing null hypothesis against hypothesis 1 :

If the significant level of test is lower than 0.05 , then it is assumed to reject null hypothesis and accept hypothesis 1.

Table 1. The results of Pearson Correlation test for finding any relationship between both variants of efficiency and social capital

\begin{tabular}{|l|c|c|}
\hline \multirow{2}{*}{ Efficiency \& Social Capital } & \multicolumn{2}{|c|}{ Testing of main hypothesis } \\
\cline { 2 - 3 } & Pearson correlation coefficient & Significant Level \\
\cline { 2 - 3 } & 0.251 & 0.002 \\
\hline
\end{tabular}

As it is obvious in Table 1, the correlation coefficient of both concerned variants is equal to 0.251 and relevant probable amount of significant level is $\mathbf{0 . 0 0 2}$ which is lower than $\mathbf{0 . 0 5}$. Therefore it is assumed to reject statistical null hypothesis about lack of any significant relationship between both variants of the study. Then it is accepted to have a significant relationship between both concerned variants.

\section{*Indirect hypothesis I:}

Research hypothesis:

-There is a significant relationship between binding social capital and upgrading of human force efficiency at Islamic Azad University-Chaloos Branch.

Null hypothesis:

-There is not a significant relationship between binding social capital and upgrading of human force efficiency at Islamic Azad University-Chaloos Branch.

If we assume:

Y: Efficiency

$\mathrm{X}$ : Binding social capital

$\rho$ : Real correlation coefficient between both variants of efficiency \& binding social capital at Islamic Azad University-Chaloos Branch. 
Table 2. The results of Pearson Correlation test for finding any relationship between both variants of efficiency and binding social capital

\begin{tabular}{|l|c|c|}
\hline \multirow{2}{*}{ Efficiency \& Binding social capital } & \multicolumn{2}{|c|}{ Testing of indirect hypothesis I } \\
\cline { 2 - 3 } & Pearson correlation coefficient & Significant Level \\
\cline { 2 - 3 } & 0.249 & 0.002 \\
\hline
\end{tabular}

As it is obvious in table 2, the correlation coefficient of both concerned variants is equal to 0.249 and relevant probable amount of significant level is $\mathbf{0 . 0 0 2}$ which is lower than $\mathbf{0 . 0 5}$. Therefore it is assumed to reject null hypothesis about lack of any significant relationship between both considered variants. In other words, the research hypothesis is accepted and there is a significant relation between both variants.

\section{*Indirect hypothesis II:}

Research hypothesis:

- There is a significant relationship between bridging social capital and upgrading of human force efficiency at Islamic Azad University-Chaloos Branch.

Null hypothesis:

- There is not a significant relationship between bridging social capital and upgrading of human force efficiency at Islamic Azad University-Chaloos Branch.

If we assume:

Y: Efficiency

$\mathrm{X}$ : Bridging social capital

$\rho$ : Real correlation coefficient between both variants of efficiency \& bridging social capital at Islamic Azad University-Chaloos Branch. 
Table 3. The results of Pearson Correlation test for finding any relationship between both variants of efficiency and bridging social capital

\begin{tabular}{|l|c|c|}
\hline \multirow{2}{*}{ Efficiency \& Bridging social capital } & \multicolumn{2}{|c|}{ Testing of indirect hypothesis II } \\
\cline { 2 - 3 } & Pearson correlation coefficient & Significant Level \\
\cline { 2 - 3 } & 0.257 & 0.001 \\
\hline
\end{tabular}

As it is obvious in table 3, the correlation coefficient of both concerned variants is equal to 0.257 and relevant probable amount of significant level is $\mathbf{0 . 0 0 1}$ which is lower than $\mathbf{0 . 0 5}$. Therefore it is assumed to reject null hypothesis about lack of any significant relationship between both considered variants. In other words, the research hypothesis is accepted and there is a significant relation between both variants.

\section{*Indirect hypothesis III:}

Research hypothesis:

- $\quad$ There is a significant relationship between linking social capital and upgrading of human force efficiency at Islamic Azad University-Chaloos Branch.

Null hypothesis:

- $\quad$ There is not a significant relationship between linking social capital and upgrading of human force efficiency at Islamic Azad University-Chaloos Branch.

If we assume:

Y: Efficiency

$\mathrm{X}$ : Linking social capital

$\rho$ : Real correlation coefficient between both variants of efficiency \& linking social capital at Islamic Azad University-Chaloos Branch. 
Table 4. The results of Pearson Correlation test for finding any relationship between both variants of efficiency and linking social capital

\begin{tabular}{|l|c|c|}
\hline \multirow{2}{*}{ Efficiency \& Bridging social Capital } & \multicolumn{2}{|c|}{ Testing of indirect hypothesis II } \\
\cline { 2 - 3 } & Pearson correlation coefficient & Significant Level \\
\cline { 2 - 3 } & 0.311 & 0.000 \\
\hline
\end{tabular}

As it is obvious in table 4, the correlation coefficient of both concerned variants is equal to $\mathbf{0 . 3 1 1}$ and relevant probable amount of significant level is $\mathbf{0 . 0 0 0}$ which is lower than $\mathbf{0 . 0 5}$. Therefore it is assumed to reject null hypothesis about lack of any significant relationship between both considered variants. In other words, the research hypothesis is accepted and there is a significant relation between both variants.

*Freedman test for classification of social capital variants:

Table 5. The results of Freedman test for social capital dimensions

\begin{tabular}{|c|c|c|}
\hline No. & Type of social capital & Average grade \\
\hline 1 & Binding social capital & 2.80 \\
\hline 2 & Bridging social capital & 1 \\
\hline 3 & Linking social capital & 2.20 \\
\hline
\end{tabular}

\begin{tabular}{|c|c|c|c|c|}
\hline Asymp.Sig. & df & N & Chi-Square & Test \\
\hline 0.000 & 2 & 135 & $232 / 132$ & Friedman \\
\hline
\end{tabular}

Table 5 illustrates the calculated Chi-Square for Freedman test with a probability of \%99 as well. As a result, the effect of binding social capital with an average grade of 2.80 is more than other parameters. Then we have bridging social capital and linking social capital in next classes. 


\section{Proposals out of direct findings}

The results suggest the following conclusion remarks;

1) All managers of Islamic Azad University-Chaloos Branch are obliged to believe that qualitative concepts should be specified in the form digits in order to have better management.

2) Regarding the current strategies at Islamic Azad University-Chaloos Branch for upgrading of quality, it is obvious that it is impossible except by having powerful and responsible human force. The mentioned human force may cause a form of synergy for good interaction which is the same social capital. Therefore it may illustrate the importance of social capital among all levels of consideration.

3) The manager of Islamic Azad University-Chaloos Branch is obliged to measure social capital in order to recognize its rate accordingly. Certainly encouraging of all members by manager may increase the survival of social capital as well.

4) It means only encouraging of those persons who may cause more social capital at different parts of the university is not enough but we do not ignore punishment as well. Those departments with little social capital should not be encouraged like the same with higher social capital.

5) Regarding the role of managers in creation and upgrading of social capital, it is necessary to recognize and encourage those managers of Islamic Azad University-Chaloos Branch with positive characteristics for upgrading of social capital.

6) Those managers and persons in charge who may endanger social capital of the organization should be removed and/or punished in order to provide a suitable space for others.

7) We should believe that one of the most important cultural activities at present is considering the concept of social capital. Therefore the manager is obliged to write some cultural programs for making such a critical case as much as possible.

8) Cultural assistant of Islamic Azad University-Chaloos Branch is obliged to provide necessary conditions for holding of conferences and seminars for discussions and scientific / special gathering and also cultural centers for finding necessary skills and further upgrade and maintenance of social capital.

9) The manager of Islamic Azad University-Chaloos Branch are obliged to encourage those manager and personnel through a glorious ceremony who may cause upgrade of social capital. This will make it possible to have suitable culture making. 
10) It is proposed to cultural assistant of Islamic Azad University-Chaloos Branch to increase mode of sacrifice and other cultural/Islamic values through some fundamental and applicable programs.

11) Regarding the special position of participation in Islam and its importance in society and low level of which among organizational people, it is necessary for managers of university to upgrade participation mode among their personnel and reduce any bureaucracy and increase the scope of supervision and involve the specialists in any administrative making decisions and accepting their proposals. In other words, it is necessary to remove any centralization in these parts.

12) All units and university centers are obliged to publish a domestic media for which all personnel and managers should discuss the case in order to publish only the ideas of specialists and managers for making more effective media. The items of media should be in compliance with personal needs and more cooperation and integration of people.

13) Holding of fairs and cultural/artistic weeks with complete attraction for specialists and managers.

14) Regarding the low level of presented grades in questionnaire, it is necessary to review the symbols. It is proposed to recognize and advertise all accepted symbols by the personnel.

15) It is recommended to recognize all accepted values by society and specialists and managers of university centers in order to apply them for increasing of social capital.

16) Since there is a medium level of safety among specialists, it is necessary to have further programs to increase safety feeling in working environment.

17) In order to increase social capital rate among personnel, it is necessary to have a sincere and fresh working environment without any lack of confidence among personnel.

\section{References}

Aspin, L. (2004). Social Capital and Productivity. Teaching and Learning Research Program, $1-34$.

Baron, R. A. \& Markman, G. D. (2003). Beyond social capital: The role of entrepreneurs' social competence in their financial success. Journal of Business Venturing, 18(1), 41-60. 
Bourdieu, P. (1986). The forms of capital. Handbook of Theory and Research for the Sociology of Education, pp. 241-258. New York: Greenwood Press.

Brooks, K. \& Muyia Nafukho, F. (2006). Human resource development, social capital, emotional intelligence. Journal of European Industrial Training, 30. ABI/INFORM Global.

Burt, R. (1992). Structural holes: The social structure of competition. Cambridge: Harvard University Press.

Cappelli, P. (2002). Social Capital and Retraining. University of Pennsylvania, Philadelphia.

Coleman, J. S. (1988). Social Capital in the Creation of Human Capital. American Journal of Sociology, (94), 95-120.

Cusack, T. R. (1997). Social Capital, Institutional Structures and Democratic Performance: A Comparative Study of German Local Governments. Discussion Paper FS III 97-201, Wissenschaftszentrum Berlin für Sozialforschung - WZB.

Flora, C. B. (1999). Building Social Capital. North central regional center for rural development. Iowa State University.

Greve, A. \& Benassi, M. (2003). Exploring the contributions of human and social capital to productivity. Hawaii International Conference on System Sciences, January 5-8, Hilton Waikoloa Village, Big Island, Hawaii.

Putnam, R. D. (2000). Bowling Alone: the collapse and revival of American community. New York: Simon and Schuster.

Sabatini, F. (2005). Does Social Capital Improve Labor Productivity in Small and Medium Enterprises. International Journal of Management and Decision Making, December, 1-29. 